\title{
Review
}

Pathobiology

Pathobiology 2007;74:89-96

DOI: $\underline{10.1159 / 000101708}$

\section{Myelofibrosis - What's in a Name?}

\section{Consensus on Definition and EUMNET Grading}

\author{
Jürgen Thiele Hans M. Kvasnicka
}

Institute of Pathology, University of Cologne, Cologne, Germany

\begin{abstract}
Key Words
Myelofibrosis $\cdot$ Semiquantitative grading $\cdot$ Chronic myeloproliferative disorders $\cdot$ Clinical implications . Dynamics $\cdot$ Prognosis $\cdot$ Bone marrow biopsies
\end{abstract}

\begin{abstract}
Objective: Myelofibrosis (MF) implies an increase in the bone marrow (BM) fiber content without referring to quantity or quality (reticulin vs. collagen). Methods: This review on chronic myeloproliferative disorders is based on initial and sequential BM biopsies, clinical data and follow-up examinations. A semiquantitative grading system for MF approved by a panel of experts was applied. Results: In chronic myelogenous leukemia, minimal reticulin to advanced collagen MF is detectable at presentation in about $30 \%$ of patients. Significant correlations between BM and clinical features, but especially prognosis, are evident. Chronic idiopathic MF includes a prodromal stage showing no or little reticulin and no relevant MF with myeloid metaplasia (MMM). A stepwise evolution is demonstrable and associated with corresponding clinical data. Usually MMM is the diagnostic guideline for this disorder and consequently early stages with accompanying thrombocytosis may clinically mimic essential thrombocythemia. MF of various degrees may be observed in polycythemia vera depending on the progress of disease. Terminal stages (spent phase) reveal overt collagen corresponding with MMM. If diagnosis of es-
\end{abstract}

sential thrombocythemia regards characteristic BM features, no relevant MF is seen at presentation and transformation into MMM is neglectable for many years. Conclusion: To recognize dynamics of the disease process in chronic myeloproliferative disorders, an easily to reproduce scoring system for MF has been proposed. The clinical diagnosis of MMM does not include initial-early reticulin MF and therefore fails to detect prodromal stages.

Copyright $\odot 2007$ S. Karger AG, Basel

\section{Introduction}

By definition, myelofibrosis (MF) implies an increase in the bone marrow (BM) fiber content without explicit reference to quantity or quality (reticulin versus collagen fibers). Causes of MF may be variable and include a multitude of reactive as well as neoplastic disorders (table 1). There is general agreement that MF is consistent with a concomitant, secondary cause, in particular with regard to the clonally transformed hematopoiesis in chronic myeloproliferative disorders (CMPDs) [1-4]. Fibrillogenesis was found to be mediated by complex cytokinetriggered cell-to-cell interactions [5-7]. Because MF is an unfavorable, often lethal complication at presentation and during follow-up in CMPDs, a clear-cut assessment of this phenomenon featured by a standardized methodology seems to be warranted. Up until now in the perti- 
Table 1. Possible cause of MF

A Reactive causes

1 Autoimmune disorders

Systematic lupus erythematosis

Scleroderma

2 Toxic

Benzene exposure

Ionizing radiation

B Osteopathies

Vitamin D deficiency

Osteopetrosis

Hypothyroidism

Renal osteodystrophy

C Infections

Tuberculosis

Sarcoidosis

Acquired immune deficiency syndrome

D Neoplastic etiology

1 Malignant lymphomas (hairy cell leukemia, follicular lymphoma, Hodgkin's lymphoma)

2 Chronic myeloproliferative diseases

3 Myelodysplastic syndromes

4 Metastasizing carcinomas

5 Acute leukemias (acute megakaryocytic leukemia)

Table 2. Consensus on the representativity of a BM trephine

Non-tangential biopsy

At least $1.5 \mathrm{~cm}$ in length

Optimal thickness of sections: $3-4 \mu \mathrm{m}$

Table 3. Consensus on assessment of BM cellularity (normal values)

\begin{tabular}{ll}
\hline Age & Hematopoietic area ${ }^{1}, \%$ \\
\hline $20-30$ & $60-70$ \\
$40-60$ & $40-50$ \\
$\geq 70$ & $30-40$ \\
\hline
\end{tabular}

${ }^{1}$ Disregard the first two subcortical BM lacunae, if hypocellular.

nent literature, different means of evaluations were reported that comprised morphometry [8-10] and semiquantitative gradings using different scores [11-14]. For this reason, several experts tried to reach a consensus
Table 4. Semiquantitative grading system regarding quantity and quality of MF according to a consensus of European experts [15]

\begin{tabular}{ll}
\hline Grading & Description $^{1}$ \\
\hline MF-0 & $\begin{array}{l}\text { Scattered linear reticulin with no intersections } \\
\text { (crossovers) corresponding to normal BM }\end{array}$ \\
\hline MF-1 & $\begin{array}{l}\text { Loose network of reticulin with many intersections, } \\
\text { especially in perivascular areas }\end{array}$ \\
\hline MF-2 & $\begin{array}{l}\text { Diffuse and dense increase in reticulin with extensive } \\
\text { intersections, occasionally with only focal bundles of } \\
\text { collagen and/or focal osteosclerosis }\end{array}$ \\
\hline MF-3 & $\begin{array}{l}\text { Diffuse and dense increase in reticulin with extensive } \\
\text { intersections, often associated with focal bundles of } \\
\text { collagen and/or focal osteosclerosis }\end{array}$ \\
\hline \multicolumn{1}{l}{ Fiber density should be assessed in hematopoietic (cellular) } \\
areas.
\end{tabular}

Table 5. Diagnostic criteria for MF with MMM

Progressive anemia

Splenomegaly

Teardrop poikilocytosis

Leukoerythroblastosis

BM (collagen) fibrosis

based on a simplified and easily reproducible semiquantitative grading system [15]. However, before quantifying the BM fiber content, basic parameters had to be regarded by defining a representative biopsy specimen (table 2) or the age-matched cellularity (table 3). Following these postulates an appropriate semiquantitative scoring and assessment of reticulin and collagen was accomplished (table 4). The restriction to only four grades and inclusion of osteosclerotic lesions (fig. 1a-d) renders an easy recognition and reproducibility. However, in this context a most important point should be emphasized, namely the significant discrepancy between the morphological term MF and the clinical definition which includes laboratory features associated with extramedullary hematopoiesis (table 5) implicating MF with myeloid metaplasia (MMM) [16-20]. For this reason, early (prodromal) stages of reticulin fibrosis are not detected by the clinicians and consequently dynamics of the disease process as well as possible therapy effects will only be unveiled when regularly performing a BM biopsy including follow-up examinations. 
Fig. 1. Grading of $M F$ as evidenced in CIMF. a MF-0, b MF-1, c MF-2, d MF-3 (see also tables 7 and 8). Gomori's silver impregnation. $\times 180$.
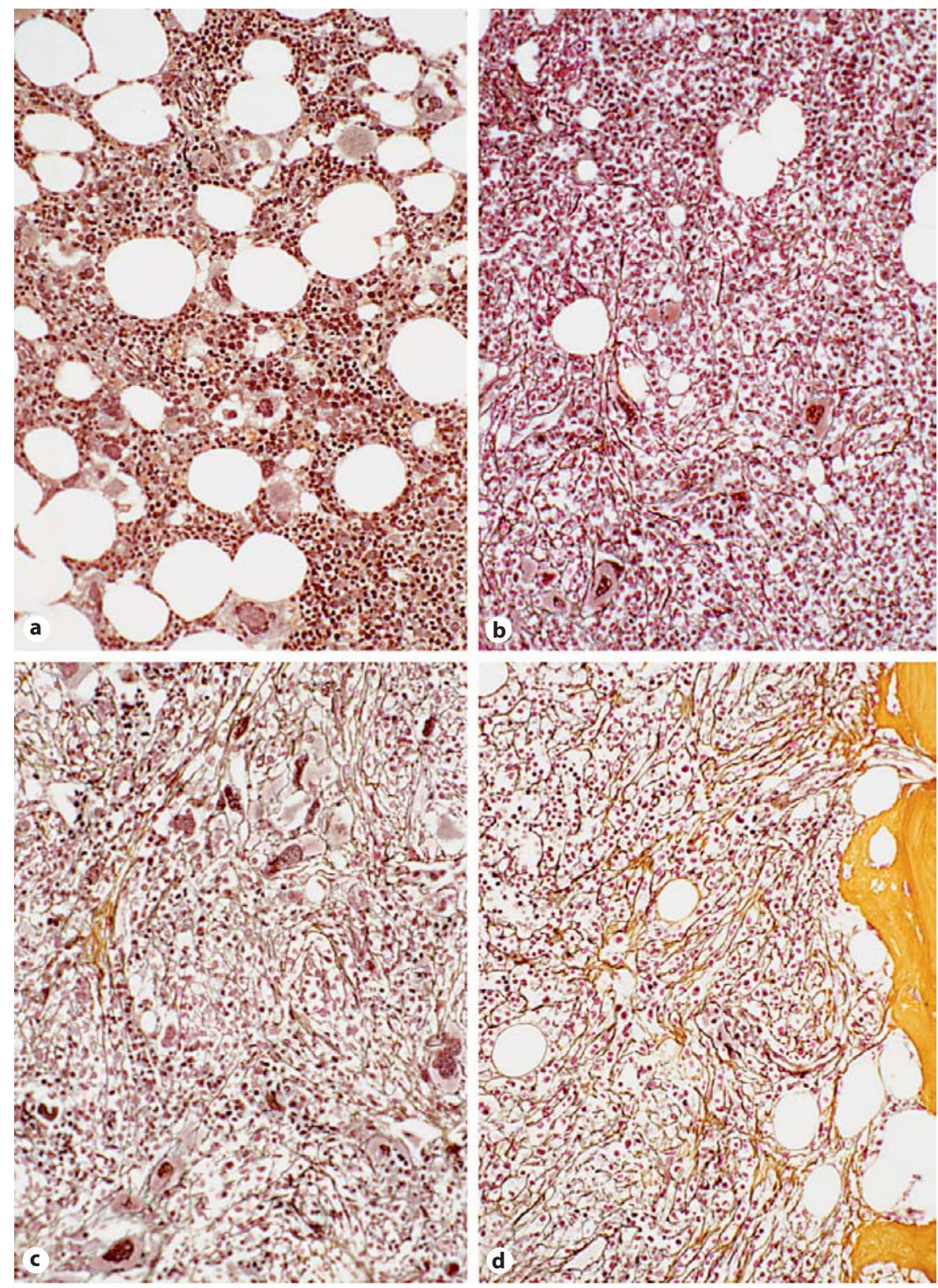

\section{Clinical Implications}

Regarding chronic myelogenous leukemia (CML), a minimal reticulin (MF-1) to advanced collagen fibrosis (MF-3) may be present on admission in up to $30 \%$ of patients $[10,13,21,22]$. Concerning clinical data it is noteworthy that significant differences exist between the majority of patients without MF (table 6) and those with relevant reticulin and collagen fibrosis (MF-2/MF-3). Moreover, quantity of the small dwarf-like atypical mega- karyocytes characteristic for this disorder displays a close relationship with the presence of MF [22-24]. Few patients may even present with a peripheral blast count less than $10 \%$ and no clinical signs and symptoms of acceleration or blastic crisis $[25,26]$ but a relevant MF (table 6). On the other hand, in retrospectively performed evaluations and prospective clinical trials a mild to overt increase in MF was repeatedly reported to indicate an independent factor of predictive value regarding survival $[10,13,23,27]$. Changes in the extent of MF is signifi- 
Table 6. Clinical findings (mean values) in 584 patients with stable phase CML at presentation according to their degree of MF

\begin{tabular}{lrrrr}
\hline & MF-0 & MF-1 & MF-2 & MF-3 \\
\hline Patients & 357 & 171 & 36 & 20 \\
Hemoglobin, g/dl & 12.8 & 11.9 & 11.0 & 10.3 \\
Leukocytes, $\times 10^{9} / 1$ & 93 & 118 & 137 & 83 \\
Thrombocytes, $\times 10^{9} / 1$ & 423 & 434 & 537 & 486 \\
Basophils & 3.4 & 3.7 & 5.3 & 9.1 \\
Peripheral blasts & 2.1 & 2.8 & 3.5 & 4.5 \\
Palpable spleen, cm below & & & & \\
$\quad$ costal margin & 2.5 & 3.4 & 4.1 & 11.2 \\
\hline
\end{tabular}

Table 7. Clinical findings (mean values) in 865 patients presenting with CIMF according to their degree of MF, i.e. stages of disease

\begin{tabular}{lrrrr}
\hline & MF-0 & MF-1 & MF-2 & MF-3 \\
\hline Patients & 232 & 333 & 146 & 154 \\
Hemoglobin, g/dl & 13.9 & 13.1 & 12.0 & 10.6 \\
Leukocytes, $\times 10^{9} / 1$ & 12.4 & 12.2 & 11.0 & 10.9 \\
Thrombocytes, $\times 10^{9} / 1$ & 902 & 841 & 640 & 308 \\
Peripheral erythro-myeloblasts, $\%$ & 0.3 & 0.2 & 0.4 & 1.3 \\
$\begin{array}{l}\text { Palpable spleen, cm below } \\
\quad \text { costal margin }\end{array}$ & 1.1 & 1.4 & 3.2 & 5.5 \\
\hline
\end{tabular}

Table 8. Dynamics of MF (at least one grade) in 309 patients with CIMF (follow-up biopsies after $36 \pm 18$ months)

\begin{tabular}{lrlll}
\hline $\begin{array}{l}\text { Grading at } \\
\text { diagnosis }\end{array}$ & Patients & \multicolumn{4}{l}{ Relative rates, \% } \\
\cline { 3 - 5 } & & regression & no change & progression \\
\hline MF-0 & 78 & 0 & 11 & 89 \\
MF-1 & 100 & 5 & 24 & 71 \\
MF-2 & 52 & 9 & 41 & 50 \\
MF-3 & 79 & 11 & 89 & - \\
\hline
\end{tabular}

Table 9. Evolution of MF (at least one grade, median follow-up 20 months) in 233 patients with CIMF in relation to therapy

\begin{tabular}{lccl}
\hline \multirow{2}{*}{ Therapy } & \multicolumn{3}{c}{ Dynamics of MF, \% } \\
\cline { 2 - 4 } & regression & stable & progression \\
\hline No or supportive & 0 & 55 & 45 \\
Hydroxyurea & 15 & 49 & 36 \\
Interferon- $\alpha$ & 5 & 55 & 40 \\
Busulfan & 17 & 44 & 39 \\
Variable & 2 & 62 & 36 \\
\hline
\end{tabular}

cantly influenced by treatment modalities. These include a stabilization or regression during hydroxyurea therapy $[10,28]$, but especially a striking fibrolysis after the application of the tyrosine kinase inhibitor imatinib mesylate [29-32]. Controversy and discussion arises about the possible fiber-reducing $[33,34]$ versus a stabilizing or enhancing effect of interferon- $\alpha[10,35,36]$. This conflict of opinion is mostly generated by comparing cohorts of patients with a history of different treatment modalities including crossover or combination therapies $[28,33]$.

In chronic idiopathic myelofibrosis (CIMF) a wealth of data has been accumulated that prodromal stages exist without clinically apparent features of MMM [21, 37-41]. Because of the often prevalent thrombocytosis in patients with early-stage CIMF [42] these cases may mimic essential thrombocythemia (ET) when following the corresponding criteria of the Polycythemia Vera Study Group (PVSG) $[43,44]$. Based on scrutinized evaluations of large cohorts of patients including the wide spectrum of disease manifestations with the extreme endpoints of prefibrotic to overt fibro-osteosclerotic terminal stages, significant differences concerning clinical data are revealed (table 7). The dynamics of CIMF generally implicate an evolution of precursor stages (table 8) to classical features of MMM [16-20] that are compatible with MF grades 2 and 3 according to clinicopathological investigations (table 7). More and more insights into a stepwise progression of CIMF was gained by a comparative analysis of sequential BM biopsies and associated hematological data $[21,37-39,41,45,46]$. Therapy-induced changes were relatively rarely reported concerning regression of MF (table 9). There seems to be a consensus that following conventional treatment with hydroxyurea or interferon- $\alpha$, no significant resolution of MMM or the BM fiber content is observable in the majority of patients [20, 39, 41, 46-50]. Concerning prognosis, prefibrotic and early fibrotic (MF-0/MF-1) stages of CIMF are associated with a more prolonged survival than those with overt MMM [51, 52]. When applying the so-called Lille score [53], the grade of MF reveals only a weak relationship with the postulated risk groups, although the majority of intermediate to high-risk patients are associated with a higher degree of MF (table 10). However, in most studies, age, hemoglobin level, peripheral blood precursor cells and leukocyte or thrombocyte counts were described as the most significant prognostic factors [18, 51-63].

Concerning polycythemia vera (PV), a borderline to overt reticulin MF may be observed in up to $20 \%$ of patients at presentation, probably depending on the progress of disease [9, 21, 41, 64-67]. Several lines of evidence 
Table 10. Risk profile (Lille score) in CIMF related to grading of MF

\begin{tabular}{lcccc}
\hline \multirow{2}{*}{$\begin{array}{l}\text { Risk group according } \\
\text { to Lille score }\end{array}$} & \multicolumn{4}{l}{ Grade of MF } \\
\cline { 2 - 5 } & MF-0 & MF-1 & MF-2 & MF-3 \\
\hline Low risk, \% & 89 & 86 & 73 & 62 \\
Intermediate risk, \% & 11 & 14 & 20 & 31 \\
High risk, \% & - & - & 7 & 7 \\
\hline
\end{tabular}

Table 11. Follow-up biopsies (mean values) and clinical findings in 76 patients with PV after an observation time of about 3 years (some of these patients entered already with a history of PV)

\begin{tabular}{lcc}
\hline & $\begin{array}{l}\text { At presentation } \\
\text { (first biopsy) }\end{array}$ & $\begin{array}{l}\text { Follow-up } \\
\text { (last biopsy) }\end{array}$ \\
\hline Hemoglobin, g/dl & & \\
$\quad$ Males & 18.8 & 15.3 \\
$\quad$ Females & 17.6 & 14.7 \\
Leukocytes, $\times 10^{9} / 1$ & 12.5 & 18.9 \\
Thrombocytes, $\times 10^{9} / 1$ & 558 & 415 \\
LAP (score) & 137 & 230 \\
Palpable splenomegaly & 2.8 & 4.1 \\
Myelofibrosis (grading: relative frequency \%) & \\
0 & 64 & 38 \\
1 & 28 & 22 \\
2 & 4 & 23 \\
3 & 4 & 17 \\
\hline
\end{tabular}

Table 12. Evolution of MF (at least one grade in BM fibrosis) according to follow-up examinations of patients (median interval 3 years) with putative ET depending on applied classification

\begin{tabular}{lll}
\hline Classification & Patients & Relative rate of progression, \% \\
\hline PVSG & & \\
ET & 476 & 28 \\
WHO & & \\
ET & 167 & 0 \\
CIMF-0 & 174 & 34 \\
CIMF-1 & 135 & 68 \\
\hline
\end{tabular}

have suggested that the significantly higher degree of MF $(36 \%)$ in pretreatment biopsies described by the PVSG [68] may be related to a later entry of patients into the trial and/or performance of the BM examinations. Especially in polycythemia vera, evolution of MF during follow-up examinations is well documented and associated with a terminal stage or postpolycythemic MMM $[21,39$, $64-66,68-70]$. Since a certain degree of (reticulin) MF is already encountered in a variable number of patients on admission, dynamics are only elucidated when regarding the rate of increase (table 11).

ET shows no relevant increase in reticulin fibers in initial BM biopsy specimens $[9,10,21,64,71-74]$. Contrasting the diagnostic criteria of the PVSG $[43,44]$, if a substantial amount of reticulin or any collagen fibers are present, the WHO classification [75] warrants a clear-cut differentiation from early-stage CIMF [24, 74, 76-78]. This feature is one of the most striking shortcomings of the UK-PT ${ }_{1}$ Study [79] and has been explicitly addressed in the corresponding editorial to this paper [80]. In another large series of 195 patients with ET, initially the PVSG criteria were applied and evolution of overt MMM occurred in only 13 cases after a median follow-up of 8 years [81]. However, in this study there is again a lack of exact data concerning a systematically conducted analysis of BM biopsies at diagnosis and follow-up and it appears that sequential examinations were only performed when patients showed already clinical signs of MMM. For this reason, early stages of reticulin or collagen fibrosis were not recognized and consequently the precursor stages of CIMF were missed $[42,72,73,82]$. According to the WHO classification [75] in so-called true ET, progression into MF is neglectable up to 5 years after diagnosis $[21,41,64,83]$. This finding is opposed to so-called false ET that includes cases with prefibrotic and earlystage CIMF (table 12) when adhering to the diagnostic guidelines of the PVSG $[43,44]$.

In conclusion, MF is a non-specific and concomitant feature of the BM due to a multitude of reactive and neoplastic causes. To recognize dynamics of the disease process and effects of therapy, an easily reproducible semiquantitative scoring system has been proposed. The clinical diagnosis of MMM does not include initial-early reticulin MF and therefore fails to detect prodromal lesions of CIMF.

\section{Acknowledgements}

This work (grading of myelofibrosis) was partially supported by a grant from the European Union-EUMNET project (QLG1CT 2002-01123). We are greatly indebted to Prof. V. Diehl, First Clinic of Medicine, University of Cologne, Germany, and his associates for providing the clinical data of their patients. Moreover, the skillful assistance of Mr. G. Simons is acknowledged. 


\section{References}

${ }_{1}$ Greenberg BR, Wilson FD, Woo L, Jenks HM: Cytogentics of fibroblastic colonies in Ph1-positive chronic myelogenous leukemia. Blood 1978;51:1039-1044.

-2 Castro-Malaspina H, Gay RE, Jhanwar SC, Hamilton JA, Chiarieri DR, Meyers PA, Gay S, Moore MA: Characteristics of bone marrow fibroblast colony-forming cells (CFU-F) and their progeny in patients with myeloproliferative disorders. Blood 1982;59:10461054.

- 3 O'Brien S, Kantariian H, Shtalrid M, Blick M, Beran M, Talpaz M: Lack of breakpoint cluster region rearrangement in marrow fibroblasts of patients with Philadelphia chromosome-positive chronic myelogenous leukemia. Hematol Pathol 1988;2:25-29.

-4 Wang JC, Lang HD, Lichter S, Weinstein M, Benn P: Cytogenetic studies of bone marrow fibroblasts cultured from patients with myelofibrosis and myeloid metaplasia. $\mathrm{Br} \mathrm{J} \mathrm{Hae}-$ matol 1992;80:184-188.

5 Yang M, Khachigian LM, Hicks C, Chesterman CN, Chong BH: Identification of PDGF receptors on human megakaryocytes and megakaryocytic cell lines. Thromb Haemost 1997;78:892-896.

6 Le Bousse-Kerdiles MC, Martyre MC: Myelofibrosis: pathogenesis of myelofibrosis with myeloid metaplasia. French INSERM Research Network on Myelofibrosis with Myeloid Metaplasia. Springer Semin Immunopathol 1999;21:491-508.

7 Martyre MC: Critical review of pathogenetic mechanisms in myelofibrosis with myeloid metaplasia. Curr Hematol Rep 2003;2:257263.

8 Thiele J, Hoeppner B, Zankovich R, Fischer $\mathrm{R}$ : Histomorphometry of bone marrow biopsies in primary osteomyelofibrosis/-sclerosis (agnogenic myeloid metaplasia) - correlations between clinical and morphological features. Virchows Arch A Pathol Anat Histopathol 1989;415:191-202.

-9 Thiele J, Kvasnicka HM, Fischer R: Histochemistry and morphometry on bone marrow biopsies in chronic myeloproliferative disorders - aids to diagnosis and classification. Ann Hematol 1999;78:495-506.

10 Buesche G, Hehlmann R, Hecker H, Heimpel H, Heinze B, Schmeil A, Pfirrmann M, Gomez G, Tobler A, Herrmann H, Kappler M, Hasford J, Buhr T, Kreipe HH, Georgii A: Marrow fibrosis, indicator of therapy failure in chronic myeloid leukemia - prospective long-term results from a randomized-controlled trial. Leukemia 2003;17:2444-2453.

-11 Bauermeister DE: Quantitation of bone marrow reticulin - a normal range. Am J Clin Pathol 1971;56:24-31.

12 Manoharan A, Horsley R, Pitney WR: The reticulin content of bone marrow in acute leukaemia in adults. Br J Haematol 1979;43: 185-190.
13 Dekmezian R, Kantarjian HM, Keating MJ, Talpaz M, McCredie KB, Freireich EJ: The relevance of reticulin stain-measured fibrosis at diagnosis in chronic myelogenous leukemia. Cancer 1987;59:1739-1743.

14 Beckman EN, Brown AW Jr: Normal reticulin level in iliac bone marrow. Arch Pathol Lab Med 1990;114:1241-1243.

15 Thiele J, Kvasnicka HM, Facchetti F, Franco V, van der Walt J, Orazi A: European consensus on grading bone marrow fibrosis and assessment of cellularity. Haematologica 2005; 90:1128-1132.

16 Cervantes F, Pereira A, Esteve J, Cobo F, Rozman C, Montserrat E: The changing profile of idiopathic myelofibrosis: a comparison of the presenting features of patients diagnosed in two different decades. Eur J Haematol 1998;60:101-105.

17 Barosi G, Ambrosetti A, Finelli C, Grossi A, Leoni P, Liberato NL, Petti MC, Pogliani E, Ricetti M, Rupoli S, Visani G, Tura S: The Italian consensus conference on diagnostic criteria for myelofibrosis with myeloid metaplasia. Br J Haematol 1999; 104:730-737.

18 Barosi G: Myelofibrosis with myeloid metaplasia: diagnostic definition and prognostic classification for clinical studies and treatment guidelines. J Clin Oncol 1999;17:29542970.

19 Tefferi A: Myelofibrosis with myeloid metaplasia. N Engl J Med 2000;342:1255-1265.

20 Dingli D, Mesa RA, Tefferi A: Myelofibrosis with myeloid metaplasia: new developments in pathogenesis and treatment. Intern Med 2004;43:540-547.

21 Georgii A, Buesche G, Kreft A: The histopathology of chronic myeloproliferative diseases. Baillieres Clin Haematol 1998;11:721749.

22 Thiele J, Kvasnicka HM, Fischer R: Bone marrow histopathology in chronic myelogenous leukemia - evaluation of distinctive features with clinical impact. Histol Histopathol 1999;14:1241-1256.

23 Lazzarino M, Morra E, Castello A, Inverardi D, Coci A, Pagnucco G, Magrini U, Zei G, Bernasconi C: Myelofibrosis in chronic granulocytic leukaemia: clinicopathologic correlations and prognostic significance. $\mathrm{Br}$ J Haematol 1986;64:227-240.

24 Buhr T, Choritz H, Georgii A: The impact of megakaryocyte proliferation of the evolution of myelofibrosis. Histological follow-up study in 186 patients with chronic myeloid leukaemia. Virchows Arch A Pathol Anat Histopathol 1992;420:473-478.

25 Muehleck SD, McKenna RW, Arthur DC, Parkin JL, Brunning RD: Transformation of chronic myelogenous leukemia: clinical, morphologic, and cytogenetic features. Am J Clin Pathol 1984;82:1-14.
26 Faderl S, Talpaz M, Estrov Z, Kantarjian HM: Chronic myelogenous leukemia: biology and therapy. Ann Intern Med 1999;131: 207-219.

27 Kvasnicka HM, Thiele J, Schmitt-Graeff A, Diehl V, Zankovich R, Niederle N, Leder LD, Schaefer HE: Bone marrow features improve prognostic efficiency in multivariate risk classification of chronic-phase $\mathrm{Ph}^{1+}$ chronic myelogenous leukemia: a multicenter trial. J Clin Oncol 2001;19:2994-3009.

28 Thiele J, Kvasnicka HM, Schmitt-Graeff A, Spohr M, Diehl V, Zankovich R, Niederle N, Leder LD: Effects of interferon and hydroxyurea on bone marrow fibrosis in chronic myelogenous leukaemia: a comparative retrospective multicentre histological and clinical study. Br J Haematol 2000;108:64-71.

29 Beham-Schmid C, Apfelbeck U, Sill H, Tsybrovsky O, Hofler G, Haas OA, Linkesch W: Treatment of chronic myelogenous leukemia with the tyrosine kinase inhibitor STI571 results in marked regression of bone marrow fibrosis. Blood 2002;99:381-383.

30 Hasserjian RP, Boecklin F, Parker S, Chase A, Dhar S, Zaiac M, Olavarria E, Lampert I, Henry K, Apperley JF, Goldman JM: ST1571 (imatinib mesylate) reduces bone marrow cellularity and normalizes morphologic features irrespective of cytogenetic response. Am J Clin Pathol 2002;117:360-367.

31 Bueso-Ramos CE, Cortes J, Talpaz M, O’Brien S, Giles F, Rios MB, Medeiros LJ, Kantarjian H: Imatinib mesylate therapy reduces bone marrow fibrosis in patients with chronic myelogenous leukemia. Cancer 2004;101:332-336.

32 Thiele J, Kvasnicka HM, Schmitt-Graeff A, Kriener S, Engels K, Staib P, Ollig ES, Keller C, Fokkema S, Griesshammer M, Waller CF, Ottmann OG, Hansmann ML: Bone marrow changes in chronic myelogenous leukaemia after long-term treatment with the tyrosine kinase inhibitor STI571: an immunohistochemical study on 75 patients. Histopathology 2005;46:540-550.

33 Thiele J, Kvasnicka HM, Niederle N, Zirbes TK, Schmidt M, Dammasch J, Meuter BR, Leder LD, Kloke O, Diehl V, et al: The impact of interferon versus busulfan therapy on the reticulin stain-measured fibrosis in chronic myelogenous leukemia - a comparative morphometric study on sequential trephine biopsies. Ann Hematol 1995;70:121-128.

34 Facchetti F, Tironi A, Marocolo D, Capucci A, Ruggeri G, Bellotti D, Rossi G: Histopathological changes in bone marrow biopsies from patients with chronic myeloid leukaemia after treatment with recombinant $\alpha$-interferon. Histopathology 1997;31:3-11. 
-35 Straetmans N, Ma DD, Nevell DF, Arthur C: Evolution of bone marrow fibrosis and stromal antigenic expression in chronic myeloid leukemia on $\alpha$-interferon and Ara-C therapy. Hematopathol Mol Hematol 1996;10: 213-222.

-36 Wilhelm M, Bueso-Ramos C, O’Brien S, Pierce S, Keating M, Talpaz M, Kantarjian HM: Effect of interferon- $\alpha$ therapy on bone marrow fibrosis in chronic myelogenous leukemia. Leukemia 1998;12:65-70.

-37 Thiele J, Zankovich R, Steinberg T, Fischer R, 52 Diehl V: Agnogenic myeloid metaplasia correlation of bone marrow lesions with laboratory data: a longitudinal clinicopathological study on 114 patients. Hematol Oncol 1989;7:327-343.

-38 Thiele J, Kvasnicka HM, Boeltken B, Zankovich R, Diehl V, Fischer R: Initial (prefibrotic) stages of idiopathic (primary) myelofibrosis - a clinicopathological study. Leukemia 1999; 13:1741-1748.

39 Buhr T, Busche G, Choritz H, Langer F, Kreipe $\mathrm{H}$ : Evolution of myelofibrosis in chronic idiopathic myelofibrosis as evidenced in sequential bone marrow biopsy specimens. Am J Clin Pathol 2003;119:152158.

-40 Thiele J, Kvasnicka HM: Prefibrotic chronic idiopathic myelofibrosis - a diagnostic enigma? Acta Haematol 2004;111:155-159.

-41 Kreft A, Buche G, Ghalibafian M, Buhr T, Fischer T, Kirkpatrick CJ: The incidence of myelofibrosis in essential thrombocythaemia, polycythaemia vera and chronic idiopathic myelofibrosis: a retrospective evaluation of sequential bone marrow biopsies. Acta Haematol 2005;113:137-143.

-42 Thiele J, Kvasnicka HM: Chronic myeloproliferative disorders with thrombocythemia: a comparative study of two classification systems (PVSG, WHO) on 839 patients. Ann Hematol 2003;82:148-152.

-43 Pearson TC: Diagnosis and classification of erythrocytoses and thrombocytoses. Baillieres Clin Haematol 1998;11:695-720.

-44 Murphy S: Diagnostic criteria and prognosis in polycythemia vera and essential thrombocythemia. Semin Hematol 1999;36:9-13.

-45 Thiele J, Kvasnicka HM, Zankovich R, Diehl $\mathrm{V}$ : Early-stage idiopathic (primary) myelofibrosis - current issues of diagnostic features. Leuk Lymphoma 2002;43:1035-1041.

-46 Thiele J, Kvasnicka HM, Schmitt-Graeff A, Diehl V: Dynamics of fibrosis in chronic idiopathic (primary) myelofibrosis during therapy: a follow-up study on 309 patients. Leuk Lymphoma 2003;44:949-953.

-47 Parmeggiani L, Ferrant A, Rodhain J, Michaux JL, Sokal G: Interferon- $\alpha$ in the treatment of symptomatic myelofibrosis with myeloid metaplasia. Eur J Haematol 1987;39: 228-232.

48 Barosi G, Liberato LN, Costa A, Ascari E: Cytoreductive effect of recombinant $\alpha$-interferon in patients with myelofibrosis with myeloid metaplasia. Blut 1989;58:271-274.
49 Lofvenberg E, Wahlin A, Roos G, Ost A: Reversal of myelofibrosis by hydroxyurea. Eur J Haematol 1990;44:33-38.

50 Thiele J, Kvasnicka HM, Schmitt-Graeff A, Diehl V: Bone marrow histopathology following cytoreductive therapy in chronic idiopathic myelofibrosis. Histopathology 2003;43:470-479.

51 Thiele J, Kvasnicka HM: Hematopathological findings in chronic idiopathic myelofibrosis. Semin Clin Oncol 2005;32:380-394.

Kvasnicka HM, Thiele J: The impact of clinicopathological studies on staging and survival in essential thrombocythemia, chronic idiopathic myelofibrosis, and polycythemia vera. Semin Thromb Hemost 2006;32:362371.

53 Dupriez B, Morel P, Demory JL, Lai JL, Simon M, Plantier I, Bauters F: Prognostic factors in agnogenic myeloid metaplasia: a report on 195 cases with a new scoring system. Blood 1996;88:1013-1018.

54 Barosi G, Berzuini C, Liberato LN, Costa A, Polino G, Ascari E: A prognostic classification of myelofibrosis with myeloid metaplasia. Br J Haematol 1988;70:397-401.

55 Visani G, Finelli C, Castelli U, Petti MC, Ricci P, Vianelli N, Gianni L, Zuffa E, Aloe Spiriti MA, Latagliata $\mathrm{R}$, et al: Myelofibrosis with myeloid metaplasia: clinical and haematological parameters predicting survival in a series of 133 patients. Br J Haematol 1990;75:4-9.

56 Rupoli S, Da Lio L, Sisti S, Campanati G, Salvi A, Brianzoni MF, D’Amico S, Cinciripini A, Leoni P: Primary myelofibrosis: a detailed statistical analysis of the clinicopathological variables influencing survival. Ann Hematol 1994;68:205-212.

57 Cervantes F, Pereira A, Esteve J, Rafel M, Cobo F, Rozman C, Montserrat E: Identification of 'short-lived' and 'long-lived' patients at presentation of idiopathic myelofibrosis. Br J Haematol 1997;97:635-640.

58 Kvasnicka HM, Thiele J, Werden C, Zankovich R, Diehl V, Fischer R: Prognostic factors in idiopathic (primary) osteomyelofibrosis. Cancer 1997;80:708-719.

-59 Cervantes F, Barosi G, Demory JL, Reilly J, Guarnone R, Dupriez B, Pereira A, Montserrat E: Myelofibrosis with myeloid metaplasia in young individuals: disease characteristics, prognostic factors and identification of risk groups. Br J Haematol 1998;102:684690.

60 Kvasnicka HM, Thiele J, Regn C, Zankovich R, Diehl V, Fischer R: Prognostic impact of apoptosis and proliferation in idiopathic (primary) myelofibrosis. Ann Hematol 1999; 78:65-72.

61 Okamura T, Kinukawa N, Niho Y, Mizoguchi H: Primary chronic myelofibrosis: clinical and prognostic evaluation in 336 Japanese patients. Int J Hematol 2001;73: 194-198.
62 Kreft A, Weiss M, Wiese B, Choritz H, Buhr T, Busche G, Georgii A: Chronic idiopathic myelofibrosis: prognostic impact of myelofibrosis and clinical parameters on event-free survival in 122 patients who presented in prefibrotic and fibrotic stages. A retrospective study identifying subgroups of different prognoses by using the RECPAM method. Ann Hematol 2003;82:605-611.

63 Strasser-Weippl K, Steurer M, Kees M, Augustin F, Tzankov A, Dirnhofer S, Fiegl M, Simonitsch-Klupp I, Zojer N, Gisslinger H, Ludwig H: Age and hemoglobin level emerge as most important clinical prognostic parameters in patients with osteomyelofibrosis: introduction of a simplified prognostic score. Leuk Lymphoma 2006;47:441-450.

64 Buhr T, Georgii A, Choritz H: Myelofibrosis in chronic myeloproliferative disorders. Incidence among subtypes according to the Hannover Classification. Pathol Res Pract 1993;189:121-132.

65 Georgii A, Buhr T, Buesche G, Kreft A, Choritz $\mathrm{H}$ : Classification and staging of $\mathrm{Ph}$ negative myeloproliferative disorders by histopathology from bone marrow biopsies. Leuk Lymphoma 1996;22:15-29.

66 Thiele J, Kvasnicka HM, Diehl V: Bone marrow features of diagnostic impact in erythrocytosis. Ann Hematol 2005;84:362-367.

67 Thiele J, Kvasnicka HM: Diagnostic impact of bone marrow histopathology in polycythemia vera. Histol Histopathol 2005;20: 317-328.

68 Ellis JT, Peterson P, Geller SA, Rappaport H: Studies of the bone marrow in polycythemia vera and the evolution of myelofibrosis and second hematologic malignancies. Semin Hematol 1986;23:144-155.

69 Passamonti F, Brusamolino E, Lazzarino M, Barate C, Klersy C, Orlandi E, Canevari A, Castelli G, Merante S, Bernasconi C: Efficacy of pipobroman in the treatment of polycythemia vera: long-term results in $163 \mathrm{pa}-$ tients. Haematologica 2000;85:1011-1018.

70 Kiladjian JJ, Gardin C, Renoux M, Bruno F, Bernard JF: Long-term outcomes of polycythemia vera patients treated with pipobroman as initial therapy. Hematol J 2003;4: 198-207.

71 Thiele J, Kvasnicka HM, Diehl V, Fischer R, Michiels J: Clinicopathological diagnosis and differential criteria of thrombocythemias in various myeloproliferative disorders by histopathology, histochemistry and immunostaining from bone marrow biopsies. Leuk Lymphoma 1999;33:207-218.

72 Thiele J, Kvasnicka HM, Zankovich R, Diehl $\mathrm{V}$ : Relevance of bone marrow features in the differential diagnosis between essential thrombocythemia and early stage idiopathic myelofibrosis. Haematologica 2000;85: 1126-1134. 
73 Michiels JJ, Thiele J: Clinical and pathological criteria for the diagnosis of essential thrombocythemia, polycythemia vera, and idiopathic myelofibrosis (agnogenic myeloid metaplasia). Int J Hematol 2002;76:133-145.

74 Thiele J, Kvasnicka HM: Clinicopathological criteria for differential diagnosis of thrombocythemias in various myeloproliferative disorders. Semin Thromb Hemost 2006;32: 219-230.

75 Imbert M, Pierre R, Thiele J, Vardiman JW, Brunning RD, Flandrin G: Essential thrombocythaemia; in Jaffe ES, Harris NL, Stein H, Vardiman JW (eds): WHO Classification of Tumours: Tumours of Haematopoietic and Lymphoid Tissues. Lyon, IARC Press, 2001, pp 39-41.
76 Thiele J, Kvasnicka HM, Werden C, Zankovich R, Diehl V, Fischer R: Idiopathic primary osteo-myelofibrosis: a clinico-pathological study on 208 patients with special emphasis on evolution of disease features, differentiation from essential thrombocythemia and variables of prognostic impact. Leuk Lymphoma 1996;22:303-317.

77 Thiele J, Kvasnicka HM: Diagnostic differentiation of essential thrombocythaemia from thrombocythaemias associated with chronic idiopathic myelofibrosis by discriminate analysis of bone marrow features - a clinicopathological study on 272 patients. Histol Histopathol 2003;18:93-102.

78 Thiele J, Kvasnicka HM: A critical reapprais al of the WHO classification of the chronic myeloproliferative disorders. Leuk Lymphoma 2006;47:381-396.

79 Harrison CN, Campbell PJ, Buck G, Wheatley K, East CL, Bareford D, Wilkins BS, van der Walt JD, Reilly JT, Grigg AP, Revell P, Woodcock BE, Green AR: Hydroxyurea compared with anagrelide in high-risk essential thrombocythemia. N Engl J Med 2005;353:33-45
80 Barbui T, Finazzi G: When and how to treat essential thrombocythemia. N Engl J Med 2005;353:85-86.

81 Cervantes F, Alvarez-Larran A, Talarn C, Gomez M, Montserrat E: Myelofibrosis with myeloid metaplasia following essential thrombocythaemia: actuarial probability, presenting characteristics and evolution in a series of 195 patients. Br J Haematol 2002; 118:786-790.

82 Thiele J, Kvasnicka HM, Diehl V: Standardization of bone marrow features - does it work in hematopathology for histological discrimination of different disease patterns? Histol Histopathol 2005;20:633-644.

83 Thiele J, Kvasnicka HM, Schmitt-Graeff A, Zankovich R, Diehl V: Follow-up examinations including sequential bone marrow biopsies in essential thrombocythemia: a retrospective clinicopathological study of 120 patients. Am J Hematol 2002;70:283-291. 